\title{
Assessment of geriatrics outcomes in the cardiac intensive care unit
}

\author{
Carly Fabrizio DO, Matthew C Langston DO, MS, Keshab Subedi MS, Neil J Wimmer MD, MS, \\ Usman I Choudhry DO, MPH, Luis E Urrutia MD
}

\begin{abstract}
Objective: Critically ill older adults greater than or equal to 80 years old are routinely admitted to contemporary cardiac intensive care units (CICU). Little has been reported about their outcomes when compared to the general CICU population. The primary aim of this study was to compare the mortality, length-of-stay, and disposition outcomes of elderly patients (greater or equal to 80 years old) admitted to the CICU with a younger cohort (less than 80 years old).

Methods and Results: A single-center, retrospective cohort study was conducted including 6,194 adult patients admitted to a cardiovascular intensive care unit in Newark, Delaware, from July 1, 2012, to June 30, 2019. Coronary intensive care unit (CICU) mortality, CICU length-ofstay and discharge disposition were compared between elderly patients (greater than or equal to 80 years old) and younger patients (less than 80 years old), adjusted for comorbidities.

We observed increased mortality for elderly patients (OR 1.686, Cl 1.361-2.090, $p<0.001$ ) compared with patients less than 80 years old, even after adjusting for comorbidities. Median length of stay was not statistically different between the two groups. However, the elderly patients were significantly more likely to be discharged to a facility, such as a skilled nursing facility, than those less than 80 years old (26.8\% versus $12.5 \%$, respectively, $p<0.001)$.

Conclusions: Among patients admitted to the CICU, elderly patients have higher mortality rates than those less than 80 years old. Advanced age (greater or equal to 80 years old) was not a reliable predictor of outcome in the CICU. A large proportion of elderly patients are not able to live independently at home after CICU admissions.
\end{abstract}

Keywords: octogenarians, nonagenarians, cardiac intensive care unit, elderly, ICU mortality

\section{INTRODUCTION}

As the United States population ages, the number of older adults admitted to cardiac intensive care units (CICUs) will likely continue to rise. Care of elderly patients in a CICU can be complex and requires an understanding of not only cardiovascular diseases but of conditions specific to older adults. Polypharmacy, cognitive decline, delirium, and frailty commonly impact the care of the hospitalized elderly. ${ }^{1-4}$ The modern CICU has evolved to treat multiple acute cardiovascular

Corresponding author: Carly Fabrizio Contact Information: Carly.Fabrizio@gmail.com DOI: $10.12746 /$ swrccc.v9i39.857 diseases in addition to acute coronary syndromes. As the $\mathrm{CICU}$ continues to change and accommodate increasingly older patients, it is important to understand the outcomes and characteristics of these patients in an effort to improve future care. This study investigates the mortality, discharge disposition, and length of stay of elderly patients (defined as greater than or equal to 80 years old for the purpose of this study) admitted to the CICU compared to younger (less than 80 years old) patients.

\section{Methods}

This study is a retrospective cohort study approved by ChristianaCare's Institutional Review Board under waiver of informed consent as posing minimal risk to 
patients. The study was conducted in a large tertiary care academic medical center in Newark, Delaware. Over 1,500 patients are admitted to this CICU yearly; the CICU is a sixteen-bed open model CICU that is shared between cardiac medical and cardiac surgical services.

\section{Study Population}

Patients included in this study were consecutive medical admissions over 18 years of age to the CICU between July 1, 2012, and June 30, 2019. Cardiac surgery patients were excluded from the study cohort. Demographic information, including age, sex, race, ethnicity, primary language, admission type, vasopressor use, mechanical circulatory support use, lactic acid, creatinine, left ventricular ejection fraction (LVEF), discharge disposition, Charlson-Deyo comorbidity score, Acute Physiology and Chronic Health Evaluation (APACHE) III score, ICU length of stay, and ICU mortality, were collected from the electronic medical records (EMR) data warehouse. ${ }^{5,6}$ APACHE III scores, vasopressor data, and mechanical circulatory support data were available from July 2016 onwards, accounting for $27 \%$ of the total population.

\section{Statistical Analysis}

Patient demographic and clinical variables were summarized using count and percent, mean and standard deviation, and median and interquartile range (IQR) depending on distribution. The unadjusted effect of age (less than 80 years old versus greater than or equal to 80 years old) on ICU mortality was estimated by fitting a simple logistic regression model without other covariates. A \pm multiple logistic regression model was employed to estimate the adjusted effect of age on ICU mortality.

The covariates included in the models were age, arrival day and time (weekday day [Monday-Friday 8:00-17:59] arrival versus other), sex, race, primary language (English versus other), and comorbid conditions of cerebrovascular disease, heart failure, chronic lung disease, liver disease, diabetes, renal failure, and myocardial infarction. We also adjusted for Charlson-Deyo comorbidity score. A continuous variable representing the year of admission was introduced in the model to adjust for possible temporal trends in ICU mortality. A Chi-squared test was performed to evaluate the association of age group with discharge disposition classes.

To evaluate the factors associated with the ICU length of stay (LOS), a generalized linear model (GLM) with log link function and gamma distribution was estimated. The gamma model was selected to account for the highly right-skewed distribution of the ICU LOS. For ease of interpretation, the estimates from the gamma model are presented as a ratio of expected LOS calculated as $e^{\beta}$, where $\beta$ is the regression coefficient from the gamma model. The patients who died in the $\mathrm{CICU}$ or had missing admission or discharge times were excluded in the analysis of ICU LOS. All statistical analyses were done using $\mathrm{SAS}^{\circledR}$ version $9.4 .^{7}$

\section{RESULTS}

During the study period, there were 6,194 medical patients admitted to the CICU and used for final statistical analysis. Table 1 summarizes the study population characteristics. The mean age was $64.57 \pm 14.75$ years with the average age of $60.38 \pm 12.36$ years in the less than 80 years old and $85.3 \pm 4.31$ years in the older group. There were $62.58 \%$ males in the entire cohort with $65.25 \%$ males in the less than 80 years old group compared to $49.33 \%$ male in the older group $(p<0.001)$. White race represented $73.03 \%$ of the less than 80 years old group compared to $87.88 \%$ of the older group ( $p<0.001)$. The majority of patients were English-speaking $(95.54 \%$ less than 80 years old versus $95.48 \%$ in the older group, $p=0.935$ ). Vasopressor use occurred in $2.52 \%$ of all patients, $2.62 \%$ in the less than 80 years old compared to $2.02 \%$ in the older group ( $p=0.259$ ). Mechanical circulatory support was used in $3.47 \%$ of all patients, $3.78 \%$ in the younger than 80 years old versus $1.92 \%$ in the older group $(p=$ 0.002 ). Lactic acid and creatinine values were missing in a large number of the patients. Left ventricular ejection fraction (LVEF) had a mean value of $43.38 \% \pm$ $17.16 \%$ in all patients with a LVEF of $43.21 \% \pm 17.3 \%$ in the less than 80 years old group compared to $44.20 \% \pm 16.42 \%$ in the older group. Mean CharlsonDeyo comorbidity score was $4.3 \pm 3.24$ in less than 
Table 1. Characteristics of the Study Population

\begin{tabular}{|c|c|c|c|c|}
\hline Variable & $\begin{array}{c}\text { All } \\
(n=6194)\end{array}$ & $\begin{array}{c}\text { Age }<80 \text { Years Old } \\
(n=5154)\end{array}$ & $\begin{array}{c}\text { Age } \geq 80 \text { Years Old } \\
(n=1040)\end{array}$ & P-Value* \\
\hline Age (mean, SD) & $64.57(14.75)$ & $60.38(12.36)$ & $85.38(4.31)$ & \\
\hline Gender & & & & $<0.001$ \\
\hline Male & $3876(62.58)$ & $3363(65.25)$ & $513(49.33)$ & \\
\hline Female & $2318(37.42)$ & $1791(34.75)$ & $527(50.67)$ & \\
\hline Race & & & & $<\mathbf{0 . 0 0 1}$ \\
\hline White & $4678(75.52)$ & $3764(73.03)$ & $914(87.88)$ & \\
\hline Black & $1212(19.57)$ & $1117(21.67)$ & $95(9.13)$ & \\
\hline Other & $304(4.91)$ & $273(5.30)$ & $31(2.98)$ & \\
\hline Ethnicity & & & & 0.001 \\
\hline Hispanic or Latino & $174(2.81)$ & $162(3.14)$ & $12(1.15)$ & \\
\hline Non-Hispanic or Latino & $5736(92.61)$ & $4754(92.24)$ & $982(94.42)$ & \\
\hline Unknown & $284(4.59)$ & $238(4.62)$ & $46(4.42)$ & \\
\hline Language & & & & 0.935 \\
\hline English & $5917(95.53)$ & $4924(95.54)$ & $993(95.48)$ & \\
\hline Other & $277(4.47)$ & $230(4.46)$ & $47(4.52)$ & \\
\hline Insurance Type & & & & $<0.001$ \\
\hline Commercial & $2738(44.20)$ & $2621(50.85)$ & $117(11.25)$ & \\
\hline Medicaid & $222(3.58)$ & $222(4.31)$ & 0 & \\
\hline Medicare & $3234(52.21)$ & $2311(44.84)$ & $923(88.75)$ & \\
\hline Admission Type & & & & $<0.001$ \\
\hline Elective & $186(3.00)$ & $159(3.08)$ & $27(2.60)$ & \\
\hline Emergency & $5174(83.53)$ & $4298(83.39)$ & $876(84.23)$ & \\
\hline Trauma Center $^{\dagger}$ & $24(0.39)$ & $11(0.21)$ & $13(1.25)$ & \\
\hline Urgent ${ }^{\ddagger}$ & $810(13.08)$ & $686(13.31)$ & $124(11.92)$ & \\
\hline Arrival Day time & & & & 0.050 \\
\hline Weekday Day ${ }^{\S}$ & $2465(39.80)$ & $2023(39.25)$ & $442(42.50)$ & \\
\hline Other & $3729(60.20)$ & $3131(60.75)$ & $598(57.50)$ & \\
\hline Vasopressor use & $156(2.52)$ & $135(2.62)$ & $21(2.02)$ & 0.259 \\
\hline Mechanical support device use & $215(3.47)$ & $195(3.78)$ & $20(1.92)$ & 0.002 \\
\hline Lactic Acid (mean, SD) ${ }^{\#}$ & $3.27(3.83)$ & $3.28(3.89)$ & $3.27(3.52)$ & 0.973 \\
\hline Creatinine (mean, SD) & $1.33(1.49)$ & $1.36(1.57)$ & $1.19(0.96)$ & \\
\hline Creatinine (median, IQR)** & $1.0(0.8,1.0)$ & $1.0(0.8,1.0)$ & $1.0(0.8,1.0)$ & 0.0186 \\
\hline LVEF (mean, SD) & $43.38(17.16)$ & $43.21(17.30)$ & $44.20(16.42)$ & \\
\hline LVEF (median, IQR) ${ }^{\dagger \dagger}$ & $50(30,60)$ & $50(30,60)$ & $50(30,60)$ & 0.170 \\
\hline
\end{tabular}

(continued) 
Table 1. Characteristics of the Study Population (Continued)

\begin{tabular}{|c|c|c|c|c|}
\hline Variable & $\begin{array}{c}\text { All } \\
(n=6194)\end{array}$ & $\begin{array}{c}\text { Age }<80 \text { Years Old } \\
(n=5154)\end{array}$ & $\begin{array}{c}\text { Age } \geq 80 \text { Years Old } \\
(n=1040)\end{array}$ & P-Value* \\
\hline $\begin{array}{l}\text { Charlson Comorbidity Score } \\
\text { (mean, SD) }\end{array}$ & $4.46(3.23)$ & $4.30(3.24)$ & $5.23(3.10)$ & $<0.001$ \\
\hline Apache III Score (mean, SD) & $45.82(22.50)$ & $44.65(22.45)$ & $51.37(21.97)$ & $<0.001$ \\
\hline $\begin{array}{l}\text { ICU length of stay (hour) } \\
\text { (median, IQR) }\end{array}$ & $38(22,70)$ & $38(22,70)$ & $39(22,70)$ & 0.561 \\
\hline ICU Mortality & $507(8.19)$ & $383(7.43)$ & $124(11.92)$ & $<0.001$ \\
\hline
\end{tabular}

The values are count and percentage unless otherwise mentioned.

*The P values are from Chi-squared test for categorical variables, t-test for APACHE III, Charlson Comorbidity score, and lactic acid use, and from Wilcoxon-rank sum test for creatinine, LVEF. ${ }^{\top}$ Trauma admissions were cleared by the trauma service before admission to their respective services. ${ }^{\ddagger}$ Urgent admissions represented unscheduled emergent admissions that did not originate in the emergency department; for example, scheduled elective surgery with complications, pre-admissions from home or a doctor's office, or transfers from other facilities. ${ }^{\S}$ Weekday day admissions occurred Monday-Friday 8:00-17:59. Other designates admission times outside this window. The vasopressor and mechanical support were coded as 1 and missing. ${ }^{*}$ Lactic acid data is missing for $82.7 \%$ of the population. **Creatinine is missing for $47.5 \%$ of the population. ${ }^{\dagger} \mathrm{LVEF}$ is missing for $12.37 \%$ of the population. ${ }^{\star A}$ Apache III is missing for $73.10 \%$ of the population.

80 years old group and $5.23 \pm 3.10$ in the older cohort $(p<0.001)$. The mean APACHE III score was $44.65 \pm$ 22.45 in the less than 80 years old group compared to $51.37 \pm 21.97$ in the older cohort $(p<0.001)$. ICU mortality was $7.43 \%$ for age less than 80 years old patients compared with $11.92 \%$ in the older patients $(p<0.001)$.

Univariate analysis reported in Table 3 demonstrated that for elderly patients, the odds of dying in the $\mathrm{CICU}$ were 1.68 times higher than that of patients less than 80 years old $(\mathrm{Cl} 1.361-2.09 ; p<0.001)$. When adjusting for sex, race, language, arrival day and time, Charlson-Deyo score and admission year, the odds of ICU mortality for the older patients was $1.45(\mathrm{Cl}$ 1.15-1.82) times the odds of ICU mortality for the age less than 80 years old group (Table 4). Upon evaluation of discharge disposition, there were substantially more patients discharged to home in the age less than

Table 2. Discharge Disposition by Age Group

\begin{tabular}{|l|c|c|c|}
\hline Disposition & $\begin{array}{c}\text { Age }<\text { 80 } \\
\text { Years Old } \\
(\mathbf{n}=\mathbf{5 1 5 4})\end{array}$ & $\begin{array}{c}\text { Age } \geq \mathbf{8 0} \\
\text { Years Old } \\
(\mathbf{n}=\mathbf{1 0 4 0 )}\end{array}$ & P-Value \\
\hline Self-care & $3913(75.92)$ & $496(47.69)$ & $<\mathbf{0 . 0 0 1}$ \\
\hline Other facility & $645(12.51)$ & $279(26.83)$ & \\
\hline Hospice & $213(4.13)$ & $141(13.56)$ & \\
\hline Expired & $383(7.43)$ & $124(11.92)$ & \\
\hline
\end{tabular}

80 years old group $(53.67 \%)$ compared with the older group $(25.41 \%)$. In addition, more patients were discharged/transferred to skilled nursing facilities in the older group compared to the less than 80 years old patient group $(22.14 \%$ versus $6.52 \%$, respectively). Table 2 summarizes discharge disposition between the two groups. Table 4 shows adjusted odds ratio of factors associated with ICU mortality. Age greater than or equal to 80 years old was a significant factor associated with mortality with an adjusted odds ratio 1.446 (Cl 1.151-1.817; $p=0.0015)$.

ICU length of stay was evaluated in 5,684 patients, shown in Table 5. Patients who died in the ICU were excluded from analysis. In the age less than 80 years old group, 5,146 patients had a mean LOS of 64.91 hours, median LOS 37.70 hours (SD 88.09, Q1 22.17, Q3 70.34). In the older group, 1,039 patients had a mean LOS of 57.46 hours, median LOS 38.76 hours (SD 65.47, Q1 21.43, Q3 69.71). The median length

Table 3. Univariate Analysis of Mortality

\begin{tabular}{|l|c|c|c|}
\hline \multicolumn{3}{|c|}{ Odds Ratio Estimates } \\
\hline Effect & $\begin{array}{c}\text { Point } \\
\text { Estimate }\end{array}$ & \multicolumn{2}{|c|}{$\begin{array}{c}\text { 95\% Wald } \\
\text { Confidence Limits }\end{array}$} \\
\hline Elderly & 1.686 & 1.361 & 2.090 \\
\hline
\end{tabular}

For patients $\geq 80$ years old, the odds of dying in ICU is 1.68 times that of the patients $<80$ years old $(\mathrm{p}<0.001)$. 
Table 4. Adjusted Odds Ratio (AOR) of the Factors Associated with ICU Mortality and Results from the Multiple Logistic Regression

\begin{tabular}{|l|l|l|l|c|}
\hline Effect & AOR & \multicolumn{2}{l|}{$\mathbf{9 5 \%}$ CI of AOR } & P-Value \\
\hline $\begin{array}{l}\text { Age } \geq 80 \text { years old versus } \\
<80 \text { years old }\end{array}$ & 1.446 & 1.151 & 1.817 & $\mathbf{0 . 0 0 1 5}$ \\
\hline Sex: Female versus Male & 0.879 & 0.722 & 1.070 & 0.1984 \\
\hline Race: Black versus White & 0.768 & 0.595 & 0.991 & 0.0427 \\
\hline Language: English versus Other & 0.221 & 0.155 & 0.316 & $<.0001$ \\
\hline $\begin{array}{l}\text { Arrival day and time: } \\
\text { Weekday day versus other }\end{array}$ & 0.821 & 0.678 & 0.996 & $\mathbf{0 . 0 4 4 9}$ \\
\hline Comorbidities & \multicolumn{4}{|l|}{} \\
\hline Cerebrovascular Disease & 1.287 & 1.034 & 1.602 & $\mathbf{0 . 0 2 4 0}$ \\
\hline Congestive heart failure & 1.272 & 1.022 & 1.584 & $\mathbf{0 . 0 3 1 2}$ \\
\hline Chronic lung disease & 1.041 & 0.843 & 1.286 & 0.7082 \\
\hline Liver Disease & 1.871 & 1.141 & 3.067 & $\mathbf{0 . 0 1 3 0}$ \\
\hline Diabetes & 1.018 & 0.827 & 1.254 & 0.8640 \\
\hline Renal Failure & 1.374 & 1.085 & 1.741 & $\mathbf{0 . 0 0 8 5}$ \\
\hline Myocardial Infarction & 0.832 & 0.683 & 1.015 & 0.0693 \\
\hline Charlson Comorbidity Score & 1.076 & 1.031 & 1.123 & $\mathbf{0 . 0 0 0 9}$ \\
\hline Admission year & 1.001 & 0.955 & 1.050 & 0.9575 \\
\hline
\end{tabular}

After adjusting for sex, race, language, arrival day and time, comorbidities, and admission year, the odds of ICU mortality of patients older than or equal to 80 years old is 1.45 times the odds of ICU mortality of patients with age less than 80 years old (CI: 1.15-1.82, $\mathrm{p}=0.0015)$.

of stay was not statistically different between the two groups. Table 5 summarizes determinants of ICU LOS with estimates from the gamma model exponentiated for ease of interpretation. After adjusting for gender, race, language, arrival day and time, and comorbid conditions, the average length of stay of elderly patients is 0.84 times the average ICU LOS of patients less than 80 years old. Factors associated with an increased length of stay include weekday versus other admission time $\left(e^{\beta} 1.07, \mathrm{Cl} 1.02-1.12, p=0.004\right)$ and comorbidities, including cerebrovascular disease $\left(e^{\beta} 1.14, \mathrm{Cl} 1.07-1.20, p<0.001\right)$, congestive heart failure $\left(e^{\beta} 1.54, \mathrm{Cl} 1.46-1.62, p<0.001\right)$, chronic lung disease $\left(e^{\beta} 1.11, C l 1.05-1.16, p<0.001\right)$, liver disease $\left(e^{\beta} 1.36, C l 1.15-1.61, p<0.001\right)$, and renal failure $\left(e^{\beta} 1.11, C l 1.04-1.18, p=0.001\right)$.

Discharge disposition was compared between the two groups. The older patient group had $47.69 \%$ discharged home compared to $75.92 \%$ in the age less than 80 years old group $(p<0.001)$. The older patients were also more likely to be discharged to another facility, such as a skilled nursing facility, compared to the less than 80 years old group (26.83\% versus $12.51 \%$, respectively). Combined hospice discharge and death during hospitalization occurred in $25.48 \%$ of all older patient discharges compared with $11.56 \%$ of patients less than 80 years old.

\section{Discussion}

Our data show an increased mortality for older adult medical patients admitted to the $\mathrm{CICU}$ when compared with younger patients less than 80 years of age. The increase in mortality was noted after adjustment for measured comorbidities. Previous literature has examined the effect of age as a primary determinant of ICU outcomes, particularly in the very advanced age 
Table 5. Determinants of ICU Length of Stay: Results from the Multiple Gamma Regression Model

\begin{tabular}{|c|c|c|c|c|}
\hline Parameters & $\begin{array}{c}\mathrm{e}^{\beta} \text {-Ratio of Expected } \\
\text { LOS }\end{array}$ & \multicolumn{2}{|c|}{$95 \%$ CI of $\mathrm{e}^{\beta}$} & P-Value \\
\hline $\begin{array}{l}\text { Age greater than or equal to } 80 \text { years old versus less } \\
\text { than } 80 \text { years old }\end{array}$ & 0.84 & 0.79 & 0.89 & $<0.001$ \\
\hline Sex: Female versus Male & 0.97 & 0.93 & 1.02 & 0.280 \\
\hline Race: Black versus White & 0.97 & 0.92 & 1.03 & 0.309 \\
\hline Language: English versus Other & 1.09 & 0.96 & 1.24 & 0.188 \\
\hline $\begin{array}{l}\text { Arrival day and time: } \\
\text { Weekday day versus Other }\end{array}$ & 1.07 & 1.02 & 1.12 & 0.004 \\
\hline \multicolumn{5}{|l|}{ Comorbidities } \\
\hline Cerebrovascular Disease & 1.14 & 1.07 & 1.20 & $<0.001$ \\
\hline Congestive heart failure & 1.54 & 1.46 & 1.62 & $<0.001$ \\
\hline Chronic lung disease & 1.11 & 1.05 & 1.16 & $<0.001$ \\
\hline Liver Disease & 1.36 & 1.15 & 1.61 & $<0.001$ \\
\hline Diabetes & 1.04 & 0.98 & 1.09 & 0.172 \\
\hline Renal Failure & 1.11 & 1.04 & 1.18 & 0.001 \\
\hline Myocardial Infarction & 0.79 & 0.75 & 0.83 & $<0.001$ \\
\hline Charlson Comorbidity Score & 1.02 & 1.01 & 1.03 & 0.001 \\
\hline Admission year & 0.99 & 0.98 & 1.00 & 0.404 \\
\hline
\end{tabular}

For ease of interpretation, the estimates from the gamma model are exponentiated. The exponentiated coefficients $\left(\mathrm{e}^{\beta}\right)$ can be interpreted as a ratio of expected ICU LOS. For example, after controlling for sex, race, language, arrival day and time, and comorbid conditions, the average LOS of patients with age greater than or equal to 80 years old is 0.84 times the average ICU LOS of patients of age less than 80 years old years.

subsets (typically greater than or equal to 80 years old).$^{8-12}$ In our study, advanced age (greater or equal to 80 years old) was not seen as a reliable clinical marker for ICU mortality prediction as it had little ability to discriminate between survivors and non-survivors (ICU mortality $11.92 \%$ in the older cohort compared to $7.43 \%$ in the younger cohort).

Median CICU lengths of stay was not significantly different between the two groups. This was an unexpected finding that may benefit from further investigation. Possible explanations are that elderly patients in our cohort reached similar dispositions/decisions about their medical care goals (nursing home, hospice, etc.) or they clinically improved at a rate similar to the younger cohort.

In this study, older patients were twice as likely to be discharged to skilled nursing facilities when compared with their younger patients. Only $48 \%$ of the older patients were discharged home compared to $76 \%$ of the younger patients. This was not unexpected as advanced age in the intensive care setting is associated with increased risk of delirium, cognitive impairments, and functional deconditioning that ultimately affect discharge disposition.

This also has significant societal implications given our aging United States population. At present clinicians do not have accurate tools that can reliably assist clinicians and families in outcome predictions or discharge disposition in the older CICU patient. Clinicians and families are often left to make treatment decisions based on limited outcome data that can lead to unwanted, futile, and/or expensive medical care. Advanced age is a marker for increased CICU mortality but does not reliably predict a poor outcome. Many authors have advocated for the use of frailty scores 
with age and severity of illness calculators to assist in decision making for older patients. ${ }^{13,14}$ These tools, if used, should not only be accurate mortality predictors but also assist in predicting independent function and quality of life. Financial ramifications of futile care and end-of-life care were not evaluated in our study but should be considered in future research. ${ }^{15,16}$

\section{LIMITATIONS}

This study is limited since it is a retrospective electronic chart review and a single-center study which may prevent generalization of the results to other institutions. In addition, our analysis relied on the assumed accuracy of diagnosis coding and data entry in the electronic medical record, which can be subject to errors. This study may be prone to selection bias, as many patients of advanced age may not be admitted to the CICU due to patient goals of care preferences. Another possible limitation is that our analysis does not factor functional status, cognitive status, and frailty scores that can have prognostic value in this patient population. Many of these older patients may have been admitted from skilled nursing facilities; however, only the discharge dispositions were available for this analysis. Last, we paired patients based on Charlson-Deyo comorbidity scores and not ICU severity of illness scores. We did not use APACHE III or IV scores as they adjust for age, and this would have confounded our analysis. Future research should consider ICU specific severity of illness scores, such as the Sequential Organ Failure Assessment (SOFA), that do not include age.

\section{Conclusions}

Adult patients 80 years or older admitted to the $\mathrm{CICU}$ have a higher mortality rate than the general population. However, advanced age alone (greater or equal to 80 years old) was not a reliable predictor of outcome in the CICU given its poor ability to differentiate between survivors and non-survivors. A large proportion of elderly patients are not able to live independently at home after CICU admission. This has important societal implications given the rising number of patients reaching advanced age in our country.
Additional studies on the frailty, functional status, and outcomes of these patients post $\mathrm{CICU}$ admission are needed.

Acknowledgements: The authors would like to acknowledge invaluable assistance with database creation by Steven A. DiSabatino, James T Laughery, Prathibha K Reddy, Ann Marie Lenoir, Deborah Moore, and Marie L Cassalia.

Conflict of Interest: KS is supported by an Institutional Development Award (IDeA) from the National Institute of General Medical Sciences of the National Institutes of Health under grant number U54-GM104941 (PI: Binder-Macleod). The remaining authors have no financial disclosures or relationships with industry. No extramural funding was used to support this work.

Current affiliations: Carly Fabrizio: University of Pittsburgh Medical Center, Heart and Vascular Institute, Pittsburgh PA; Luis Urrutia: University of Pittsburgh Medical Center Pinnacle, Mechanicsburg, PA.

Article citation: Fabrizio C, Langston MC, Subedi K, Wimmer NJ, Choudhry UI, Urrutia LE. Assessment of geriatrics outcomes in the cardiac intensive care unit. The Southwest Respiratory and Critical Care Chronicles 2021;9(39):1-8

From: Heart and Vascular Institute (CF, NJW, UIC, LEU), ChristianaCare Health System, Newark DE; Department of Medicine MCL), ChristianaCare Health System, Newark DE; The Value Institute (KS), ChristianaCare Health System, Newark DE

Submitted: $3 / 1 / 2021$

Accepted: 4/6/2021

Reviewer: Jeff Dennis PhD

Conflicts of interest: none This work is licensed under a Creative Commons Attribution-ShareAlike 4.0 International License.

\section{REFERENCES}

1. Damluji AA, Forman DE, van Diepen $S$, et al. Older adults in the cardiac intensive care unit: factoring geriatric syndromes in the management, prognosis, and process of care: A Scientific Statement From the American Heart Association. Circulation 2020;141(2):e6-32. 
2. United States Census Bureau. Older People Projected to Outnumber Children [Internet]. Census.Gov. 2018; CB18-41. Available from: https://www.census.gov/newsroom/pressreleases/2018/cb18-41-population-projections.html

3. Population Reference Bureau. Fact Sheet: Aging in the United States [Internet]. 2016. Available from: http://www.prb. org/Publications/Media-Guides/2016/aging-unitedstatesfact-sheet.aspx

4. Virani SS, Alonso A, Benjamin EJ, et al. Heart Disease and Stroke Statistics-2020 Update: A Report From the American Heart Association. Circulation 2020;141(9):e139-596.

5. Deyo RA, Cherkin DC, Ciol MA. Adapting a clinical comorbidity index for use with ICD-9-CM administrative databases. J Clin Epidemiol 1992;45(6):613-9.

6. Knaus WA, Wagner DP, Draper EA, et al. The APACHE III prognostic system: Risk prediction of hospital mortality for critically III hospitalized adults. Chest 1991;100(6):1619-36.

7. SAS Institute Inc., Cary, NC U. Sas ${ }^{\circledR}$ 9.4. SAS Inst Inc, Cary, NC, USA 2017.

8. Bagshaw SM, Webb SAR, Delaney A, et al. Very old patients admitted to intensive care in Australia and New Zealand: A multi-centre cohort analysis. Crit Care 2009;13(2): R45.

9. Rockwood K, Noseworthy TW, Gibney RTN, et al. One-year outcome of elderly and young patients admitted to intensive care units. Crit Care Med 1993;21(5):687-91.
10. Boumendil A, Guidet B. Elderly patients and intensive care medicine. Intensive Care Med 2006;32(7):965-7.

11. Kaarlola A, Tallgren M, Pettilä V. Long-term survival, quality of life, and quality-adjusted life-years among critically ill elderly patients. Crit Care Med 2006;34(8):2120-6.

12. Somme D, Maillet JM, Gisselbrecht M, et al. Critically ill old and the oldest-old patients in intensive care: Short- and long-term outcomes. Intensive Care Med 2003;29(12): 2137-43.

13. Falvey JR, Ferrante LE. Frailty assessment in the ICU: translation to "real-world" clinical practice.'Anaesthesia 2019;74(6): 700-3.

14. Launey $Y$, Jacquet $H$, Arnouat $M$, et al. Risk factors of frailty and death or only frailty after intensive care in non-frail elderly patients: A prospective non-interventional study. J Intensive Care 2019;7(1).

15. Carter HE, Winch $S$, Barnett AG, et al. Incidence, duration and cost of futile treatment in end-of-life hospital admissions to three Australian public-sector tertiary hospitals: A retrospective multicentre cohort study. BMJ Open 2017; $7(10)$.

16. Downar J, You JJ, Bagshaw SM, et al. Nonbeneficial treatment Canada: Definitions, causes, and potential solutions from the perspective of healthcare practitioners. Crit Care Med 2015;43(2):270-81. 